\title{
Slip Effects on Heat and Mass Transfer of a Non-newtonian Fluid in the Micro-channel
}

\author{
Jing Zhu and Jiani Sui \\ Department of applied Mathematics, University of Science and Technology Beijing, 100083, Beijing, China
}

\begin{abstract}
The effects of velocity-slip and temperature-jump boundary conditions on Non-Newtonian flow and heat transfer in the micro channel have been investigated in this paper. The governing boundary layer equations have been transformed into a system of nonlinear differential equations through the similarity transformation, and the analytical approximations of solutions are derived by homotopy analysis method. The reliability and efficiency of the HAM solutions are verified by the residual errors. Furthermore, the effects of physical factors on the flow and heat are studied and discussed graphically.
\end{abstract}

Keywords-second grade fluid; slip-flow; velocity-slip; temperature-jump; homotopy analysis method

\section{INTRODUCTION}

During the recent years, with the rapid development of science and technology in micro- and nano-measuring technologies, it has been found that there are many significant differences between fluid flow at macro-scale and that at micro/nano-scale, such as wall-slip phenomenon. Fluids exhibiting slip are important in technological applications such as in the polishing of artificial heart valves and internal cavities. Therefore, better understanding of the phenomenon of slip is necessary. Mooney ${ }^{[1]}$ initiated the study of boundary layer flow with partial slip. M. Turkyilmazoglu ${ }^{[2]}$ has analyzed the heat and mass transfer characteristics of the mixed thermal slip MHD viscous flow. G. Singh and A.J. Chamkha ${ }^{[3]}$ have studied viscous fluid flow and heat transfer with second-order slip on a vertical permeable shrinking sheet. T.G. Fang and S.S. Yao ${ }^{[4]}$ have used a newly proposed second order slip flow model to analyze viscous flow over a shrinking sheet, and they have concluded that the second order slip flow model predicts the flow characteristic accurately. The flows of non-Newtonian fluids play an important role in many practical applications. Moreover, modeling viscoelastic flows is important for understanding and predicting the behavior of processes and thus for designing optimal flow configuration and for selecting operating conditions. B. Sahoo ${ }^{[5]}$ has considered the laminar flow and heat transfer of an electrically conducting second grade fluid with partial slip. C.Ye and X.N. Luo ${ }^{[6]}$ have come out the high-order numerical methods for heated generalized second grade fluid. I.G. Baoku and many other scholars ${ }^{[7-12]}$ also have investigated the influence of various kinds of fluid with different slip conditions. They have got a lot of constructive achievements.

In all the above-mentioned studies, little attention has been given to the effects of partial slip on the flow of a second-grade fluid in the micro channel. The main goal of this paper is to investigate the effects of the velocity-slip and temperature-jump on the flow and heat transfer characteristics of a second-grade fluid in the micro channel. Besides, mass transfer effects are also considered. Graphical results are presented and discussed by homotopy analysis method.

TABLE I. NOMENCLATURE.

\begin{tabular}{|c|c|c|c|}
\hline Symbol & description & Symbol & Description \\
\hline$u$ & $\begin{array}{l}\text { velocity components } \\
\text { along } X \text {-axis }\end{array}$ & $S_{C}$ & Schmidt number \\
\hline$v$ & $\begin{array}{l}\text { velocity components } \\
\text { along } y \text {-axis }\end{array}$ & $K$ & $\begin{array}{l}\text { normal stress } \\
\text { parameter }\end{array}$ \\
\hline$a$ & width of the channel & $\eta$ & similarity variable \\
\hline$b, k$ & constants & $\mu$ & dynamic viscosity \\
\hline$T$ & $\begin{array}{l}\text { temperature inside } \\
\text { the boundary layer }\end{array}$ & $U$ & $\begin{array}{l}\text { kinematic } \\
\text { viscosity of the } \\
\text { fluid }\end{array}$ \\
\hline$B_{0}$ & $\begin{array}{l}\text { constant magnetic } \\
\text { flux density }\end{array}$ & $\theta$ & $\begin{array}{l}\text { dimensionless } \\
\text { temperature }\end{array}$ \\
\hline$C$ & fluid concentration & $\phi$ & $\begin{array}{l}\text { dimensionless } \\
\text { concentration }\end{array}$ \\
\hline$D$ & $\begin{array}{l}\text { coefficient of mass } \\
\text { diffusivity }\end{array}$ & $k_{1}$ & $\begin{array}{l}\text { thermal diffusivity } \\
\text { of the fluid }\end{array}$ \\
\hline$T_{w}$ & $\begin{array}{l}\text { uniform temperature } \\
\text { of the fluid }\end{array}$ & $\rho$ & fluid density \\
\hline$C_{w}$ & $\begin{array}{l}\text { uniform } \\
\text { concentration of the } \\
\text { fluid }\end{array}$ & $C_{\rho}$ & $\begin{array}{l}\text { heat capacity of } \\
\text { the fluid }\end{array}$ \\
\hline$M$ & magnetic parameter & $\sigma$ & $\begin{array}{l}\text { electrical } \\
\text { conductivity }\end{array}$ \\
\hline $\operatorname{Re}$ & Reynolds number & $\alpha$ & $\begin{array}{l}\text { second-grade fluid } \\
\text { parameter }\end{array}$ \\
\hline $\operatorname{Pr}$ & Prandtl number & $\lambda$ & $\begin{array}{l}\text { velocity-slip } \\
\text { parameter }\end{array}$ \\
\hline$E c$ & Eckert number & $\beta$ & $\begin{array}{l}\text { temperature-jump } \\
\text { parameter }\end{array}$ \\
\hline
\end{tabular}

\section{MATHEMATICAL ANALYSIS}

We consider the heat and mass transfer in a boundary layer flow of a second-grade fluid in the micro channel. The coordinate system and scheme of the problem is shown in Fig.1. We consider the velocity-slip and temperature-jump conditions on the wall of the channel, the boundary conditions are:

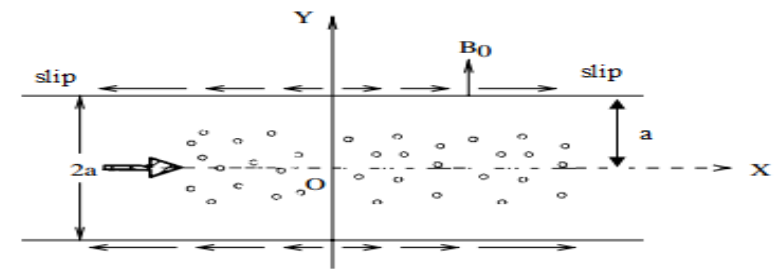

FIGURE I. PHYSICAL MODEL AND COORDINATE SYSTEM OF THE PROBLEM 


$$
\frac{\partial u}{\partial y}(x, 0)=v(x, 0)=0, \frac{\partial T}{\partial y}(x, 0)=0, C(x, 0)=C_{w}
$$

$u(x, a)=b x+\left.\frac{2-\sigma}{\sigma} \lambda\left[\frac{\partial u}{\partial y}+\frac{k_{0}}{\mu}\left(2 \frac{\partial u}{\partial x} \frac{\partial u}{\partial y}+v \frac{\partial^{2} u}{\partial y^{2}}+u \frac{\partial^{2} u}{\partial x \partial y}\right)\right]\right|_{y=a}$,

$v(x, a)=-k a b, T(x, a)=T_{s}=T_{w}+\left.\beta \frac{\partial T}{\partial y}\right|_{y=a}, C(x, a)=C_{s}$.

The governing boundary layer equations ${ }^{[13]}$ for the problem are as follows:

$$
\frac{\partial u}{\partial x}+\frac{\partial v}{\partial y}=0
$$

$u \frac{\partial u}{\partial x}+v \frac{\partial u}{\partial y}=v \frac{\partial^{2} u}{\partial y^{2}}-\frac{k_{0}}{\rho}\left[\frac{\partial}{\partial x}\left(u \frac{\partial^{2} u}{\partial y^{2}}\right)+\frac{\partial u}{\partial y} \frac{\partial^{2} v}{\partial y^{2}}+v \frac{\partial^{3} v}{\partial y^{3}}\right]-\frac{\sigma B_{0}^{2}}{\rho} u$

$\rho c_{\rho}\left(u \frac{\partial T}{\partial x}+v \frac{\partial T}{\partial y}\right)=k_{1} \frac{\partial^{2} T}{\partial y^{2}}+\mu\left(\frac{\partial u}{\partial y}\right)^{2}+k_{2} \frac{\partial u}{\partial y} \frac{\partial}{\partial y}\left(u \frac{\partial u}{\partial x}+v \frac{\partial u}{\partial y}\right)+\sigma B_{0}^{2} u^{2}$

$$
u \frac{\partial C}{\partial x}+v \frac{\partial C}{\partial y}=D \frac{\partial^{2} C}{\partial y^{2}}
$$

The mathematical analysis of the problem is simplified by introducing the following dimensionless variables:

$$
x^{*}=\frac{x}{a}, y^{*}=\frac{\eta}{a}, u=-s x^{*} f^{\prime}\left(y^{*}\right), v=s f\left(y^{*}\right), s=a b, \theta(\eta)=\frac{T-T_{s}}{T_{w}-T_{s}}, \phi(\eta)=\frac{C-C_{s}}{C_{w}-C_{s}}
$$

Substituting (8) into (1)-(7), we obtain the following ordinary differential with respect to the dimensionless variable $\eta$ :

$$
\begin{gathered}
f^{\prime \prime \prime}-M f^{\prime}+\operatorname{Re}\left(f^{\prime 2}-f f^{\prime \prime}\right)-\alpha\left(2 f^{\prime} f^{\prime \prime \prime}-f^{\prime \prime 2}-f f^{i v}\right)=0 \\
\theta^{\prime \prime}+\operatorname{Pr}\left(f \theta^{\prime}-f^{\prime} \theta\right)+E f^{\prime \prime}+M E f^{\prime^{2}}+K E q f^{\prime \prime}\left(f^{\prime} f^{\prime \prime}-f f^{\prime \prime}\right)=0 \\
\phi^{\prime \prime}-2 S c f^{\prime} \phi+S c f \phi^{\prime}=0
\end{gathered}
$$

$$
f^{\prime}(0)=f(0)=0, f^{\prime}(1)=1+\lambda\left(\dot{f}(1)\left(1+3 \alpha f^{\prime}(1)\right)-\alpha f(1) f^{\prime \prime}(1)\right),
$$

$$
f(1)=K, \theta^{\prime}(0)=0, \varphi(0)=1, \theta(1)=1+\frac{\beta}{\alpha} \theta^{\prime}(1), \varphi(1)=0 .
$$

Here $M=\frac{\sigma B_{0}^{2} a^{2}}{\mu}, R e=\frac{a^{2} b}{v}, \alpha=\frac{k_{0} b}{\mu}$

$$
\begin{gathered}
\operatorname{Pr}=\frac{\rho c_{\rho} a^{2} b}{k_{1}}, E c=\frac{\mu}{\rho c_{\rho}\left(\mathrm{T}_{w}-\mathrm{T}_{\infty}\right)}, K=\frac{k_{2}}{\mu} \quad S c=\frac{v \rho c_{\rho}}{\mu}, \\
T_{w}=T_{s}+d\left(\frac{X}{l}\right)^{2}, C_{w}=C_{s}+c\left(\frac{X}{l}\right)^{2}
\end{gathered}
$$

TABLE II. RESULTS OF SKIN FRICTION COEFFICIENT $f$ "(1)

\begin{tabular}{|l|l|l|l|l|}
\hline \multicolumn{1}{|c|}{$\lambda$} & \multicolumn{1}{c|}{$\boldsymbol{M}$} & \multicolumn{1}{c|}{$R \boldsymbol{l}$} & \multicolumn{1}{c|}{$\alpha$} & $f^{\prime \prime}(1)$ \\
\hline 1 & 6 & 10 & 0 & -0.319016 \\
\hline & & & 0.4 & -0.533620 \\
\hline & & & 0.6 & -0.625132 \\
\hline & & & 1 & -0.802046 \\
\hline 1 & 6 & 0 & 0.6 & -0.207126 \\
\hline & & & & -0.398486 \\
\hline & & & & -0.885826 \\
\hline & & & & -1.17959 \\
\hline$\lambda$ & $\boldsymbol{M}$ & $\operatorname{Re}$ & $\alpha$ & $f^{\prime \prime}(1)$ \\
\hline 1 & 0 & 10 & 0.6 & -0.625132 \\
\hline 1.5 & & & & -0.374598 \\
\hline 2 & & & & -0.267381 \\
\hline 3 & & & & -0.170035 \\
\hline 1 & 0 & 10 & 0.6 & -0.767444 \\
\hline & & & & -0.717659 \\
\hline & & & & -0.670244 \\
\hline & & & & -0.625132 \\
\hline
\end{tabular}

The local skin friction coefficient $C_{f}$ and Nusselt number $\mathrm{Nu}$ are

$$
C_{f}=\left(\frac{1+\alpha}{\operatorname{Re}}\right) f^{\prime \prime}(1), N u=-\theta^{\prime}(1)
$$

\section{APPLICATION OF HAM}

Due to the strongly nonlinear and unconventional nature of these problems above, the solving process is extraordinarily complex and we can hardly get the effective solutions. In this paper, we choose the homotopy analysis method (HAM) to get the approximate analytical solution. Homotopy analysis method is put forward by Liao $^{[14]}$ originality, it has been applied and developed by many experts ${ }^{[15-19]}$ and it has been proved to be a strong and effective mathematical method to solve weak nonlinear problems. The initial approximations are as follows:

$$
f_{0}=-\eta^{4}+2 \eta^{2}-\eta, \theta_{0}=\frac{1}{3} \eta^{3}-\frac{1}{2} \eta^{2}+\frac{7}{6}, \varphi_{0}=1+\frac{1}{2} \eta^{2}-\frac{1}{2} \eta .
$$

The liner operators are: 


$$
L_{f}=f^{i v}, L_{\theta}=\theta^{\prime \prime}, L_{\phi}=\phi^{\prime \prime} .
$$

The m-order deformation equations are constructed as follows:

$$
\begin{aligned}
& L_{f}\left[f_{m}(\eta)-\chi_{m} f_{m-1}(\eta)\right]=q h_{f} H_{f}(\eta) R_{m}(\eta) \\
& L_{\theta}\left[\theta_{m}(\eta)-\chi_{m} \theta_{m-1}(\eta)\right]=q h_{\theta} H_{\theta}(\eta) S_{m}(\eta) \\
& L_{\phi}\left[\phi_{m}(\eta)-\chi_{m} \phi_{m-1}(\eta)\right]=q h_{\phi} H_{\phi}(\eta) R_{m}(\eta)
\end{aligned}
$$

with boundary conditions:

$$
\begin{gathered}
f_{m}(0)=f_{m}^{\prime \prime}(0)=f_{m}(1)=0, \\
\theta_{m}^{\prime}(0)=0, \theta_{m}(1)=\frac{\beta}{\alpha} \theta_{m}^{\prime}(1), \phi_{m}(0)=\phi_{m}(1)=0 . \\
f_{m}^{\prime}(1)=\lambda\left(f_{m}^{\prime \prime}(1)+3 \alpha 3 \alpha\left(f_{0}^{\prime}(1) f_{m}^{\prime}(1)+f_{0}^{\prime \prime}(1) f_{m}^{\prime}(1)+\sum_{i=1}^{m-1} f_{i}^{\prime}(1) f_{m-i-1}^{\prime}\right.\right. \\
\left.-\alpha\left(f_{0}(1) f_{m}^{\prime \prime}(1)+f_{0}^{\prime \prime}(1) f_{m}(1)+\sum_{i=1}^{m-1} f_{i}(1) f_{m-i-1}^{\prime \prime}(1)\right)\right),
\end{gathered}
$$

\section{RESUlTS AND DISCUSSION}

Professor Liao has pointed that the convergence and its speed depend on the auxiliary parameters $h_{f}, h_{\theta}$ and $h_{\phi}$ to a great extent. It is straightforward to choose a proper value of $h$ which ensures that the solution series is convergent. Fig.2 has given the valid ranges: $-\mathbf{1 . 2} \leq \boldsymbol{h}_{\theta} \leq \mathbf{- 0 . 5}$, $-1.2 \leq h_{\phi} \leq-0.5$. We can also use the residual errors to help us find the proper $h$. In this paper, we define the residual error $E_{m, f}$ as the following:

$$
E_{m, f}=\int_{0}^{1}\left(f^{*}-M f^{\prime}+\operatorname{Re}\left(f^{\prime 2}-f f^{\prime}\right)-\alpha\left(2 f^{\prime \prime} f^{\prime \prime}-f^{2}-f f^{i n}\right)\right)^{2} \mathrm{~d} \eta
$$

TABLE III. RESULTS OF LOCAL NUSSELT NUMBER $\mathbf{N u}$ WITH $\lambda=1, M=6, \beta=1$.

\begin{tabular}{lccccc}
\hline$R e$ & $\alpha$ & $P r$ & $K$ & $E c$ & $N u$ \\
\hline \hline 5 & 0.6 & 0.6 & 0.3 & 0.3 & 0.649855 \\
10 & & & & & 0.444432 \\
15 & & & & & 0.303327 \\
20 & $\alpha$ & $P r$ & $K$ & $E c$ & $N u$ \\
$\operatorname{Re}$ & $\alpha$ & 0.3 & 10 & 0.3 & 1.622670 \\
10 & 0.0 & & & & 0.567186 \\
& 0.4 & & & & 0.219214 \\
& 0.8 & & & & 0.096742 \\
\hline
\end{tabular}

TABLE IV. RESULTS OF LOCAL NUSSELT NUMBER Nu WITH $\operatorname{Pr}=E c=0.3, K=10, \beta=1$.

\begin{tabular}{|lllcl|}
\hline$\lambda$ & $M$ & $R e$ & $\alpha$ & $N u$ \\
1 & 6 & 10 & 0.6 & 0.354587 \\
1.5 & & & & 0.526216 \\
2 & & & & 0.602612 \\
3 & & & $\alpha$ & 0.673742 \\
$\lambda$ & $M$ & $R e$ & $N u$ \\
1 & 0 & 10 & 0.6 & 0.011393 \\
& 2 & & & 0.025382 \\
& 4 & & & 0.165122 \\
& 6 & & & 0.317860 \\
\hline
\end{tabular}

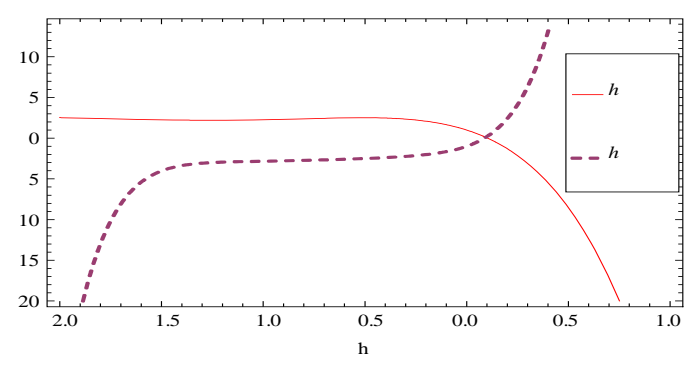

FIGURE II. $h_{\text {-CURVE OF }} \theta^{\prime}(0)$ AND $\phi^{\prime}(0)$

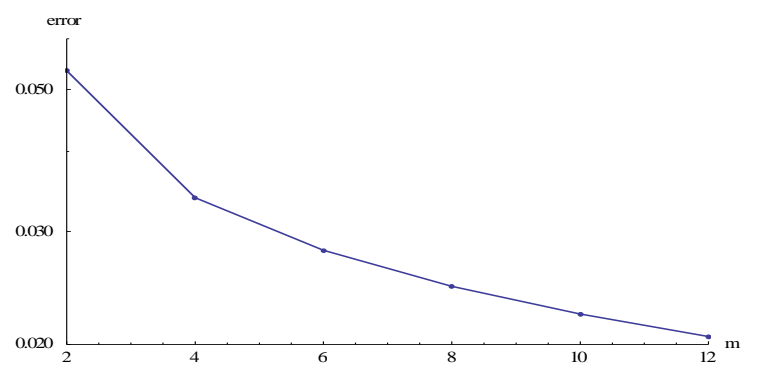

FIGURE III. THE LOGARITHMS OF THE RESIDUAL ERRORS

$$
M=R e=E c=P r=K=1
$$

Fig. 3 shows that as the order of the HAM approximation becomes higher, the residual error becomes smaller.

Table.2 shows the magnitude of the wall velocity gradient $\left|f^{\prime \prime}(1)\right|$ for different values of $R e, \alpha, M$ and $\lambda$. it is observed that as the velocity-slip parameter $\lambda$ and magnetic parameter $M$ increase, the value of $\left|f^{\prime \prime}(1)\right|$ becomes lower. That is to say the slip coefficient tends to decrease wall shear stress. It also can be seen that the combined effect of increasing the values of $\alpha$ and $R e$ is to increase wall shear stress.

Table.3-4 are made to analyze the effects of $R e, \alpha$, $M, \lambda, N u, E c, P r, K$ on the temperature gradient on the wall $\left|\theta^{\prime}(1)\right|$.The increase of $\lambda$ and $M$ lead to the increase of $\left|\theta^{\prime}(1)\right|$.

That is to say the local Nusselt number $\left|\theta^{\prime}(1)\right|$ increases when $\lambda$ and $M$ increases. It also is interesting to note that 
decreasing $\alpha$ and $R e$ tend to have high heat transfer rate. To reach a high heat transfer rate more slip and magnetic field by a liquid with a lower $\alpha$ and $R e$ number is needed.

On observing the data in Table.4, it is observed that $\lambda, \alpha, M$ and $S c$ have little effect on Sherwood number $\left|\phi^{\prime}(1)\right|$. The increase of $\lambda$ and $M$ lead to the increase of $\left|\phi^{\prime}(1)\right|$. The Schmidt number Sc tends to increase the Sherwood number by increasing concentration gradient on the wall $\left|\phi^{\prime}(1)\right|$. The reason for this trend is that the concentration boundary layer becomes thin for large $S c$ number. On the other hand $\alpha$ tends to decrease it.

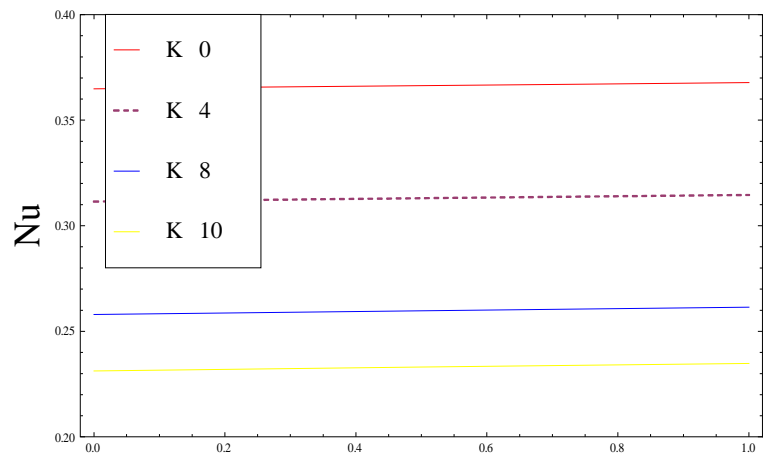

$$
\begin{gathered}
\text { FIGURE IV. }\left|\theta^{\prime}(1)\right|_{\text {WHEN }} \lambda=1, \quad \alpha=0.6, \quad R e=10, \\
M=6, \quad \operatorname{Pr}=0.6, \quad E C=, 0.3
\end{gathered}
$$

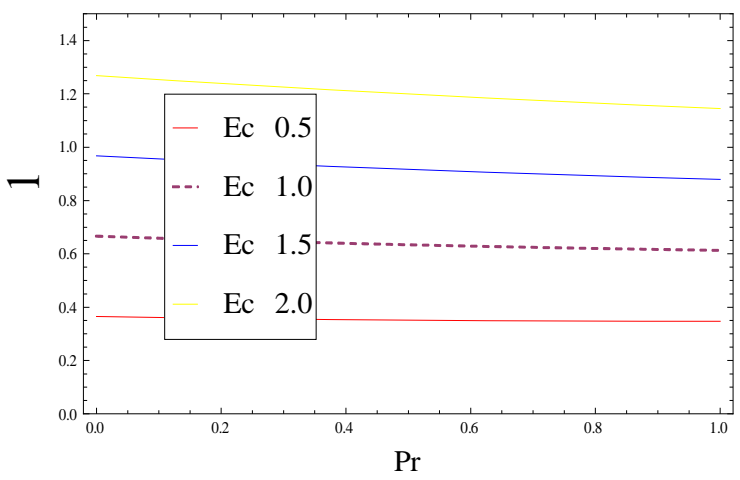

$$
\begin{aligned}
& \text { FIGURE V. }\left|\theta^{\prime}(1)\right|_{\text {WHEN }} \lambda=1, \quad \alpha=0.6, \quad R e=10 \text {, } \\
& M=6, \quad K=10, \quad \beta=1
\end{aligned}
$$

Fig.4 shows the influence of temperature-jump parameter $\beta$ and Suction/injection $K$ on the temperature gradient on the wall $\left|\theta^{\prime}(1)\right|$. It is indicated that increasing $\beta$ tends to have high heat transfer rate but $K$ decreases heat transfer rate. As a result, Nusselt number decreases by $K$ parameter.

The effect of Prandtl number parameter $\mathrm{Pr}$ on the Nusselt number $\mathrm{Nu}$ is shown by the Fig.5. It comes out that the Nusselt number $\mathrm{Nu}$ becomes lower with the increase of the Prandtl number parameter $\mathrm{Pr}$. This effect becomes little pronounced as $\mathrm{Nu}$ increases. It is not surprising as one knows that $\mathrm{Nu}$ is independent of $\mathrm{Pr}$ for no-slip laminar flow. Fig.5 also gives us the influence of the Eckert number $E c$ on the Nusselt number $\mathrm{Nu}$. From this graph, we find that the Nusselt number $\mathrm{Nu}$ increases as the value of the Eckert number $E c$ increase.

From Fig.6, it is observed that as the temperature-jump parameter $\beta$ increases, the value of $\theta(\eta)$ becomes lower. That is to say an increase in temperature-jump increases the thermal boundary layer thickness.Fig.7 shows variation of concentration in response to the change of Schmidt number parameter $S c$. With the increase of $S c$, the concentration graph increases. This matches the well-known fact that when Schmidt number becomes larger, mass transfer rate becomes faster.

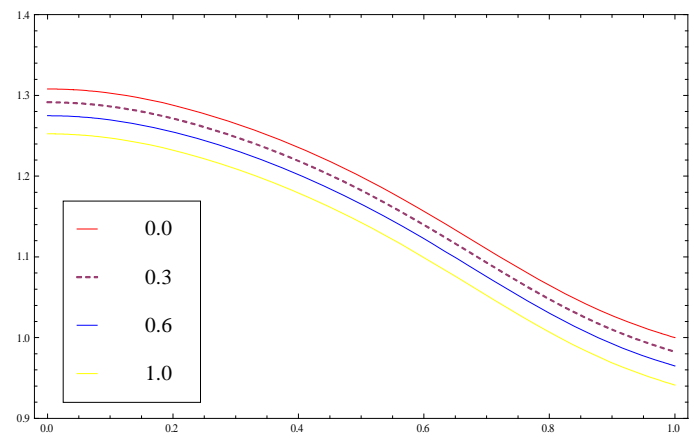

$$
\begin{aligned}
& \text { FIGURE VI. } \theta(\eta)_{\text {WITH }} \beta_{\text {WHEN }} \lambda=1, \quad \alpha=0.6, \\
& \operatorname{Re}=10, M=6, \quad K=10, \quad \operatorname{Pr}=0.6, E c=, 0.3
\end{aligned}
$$

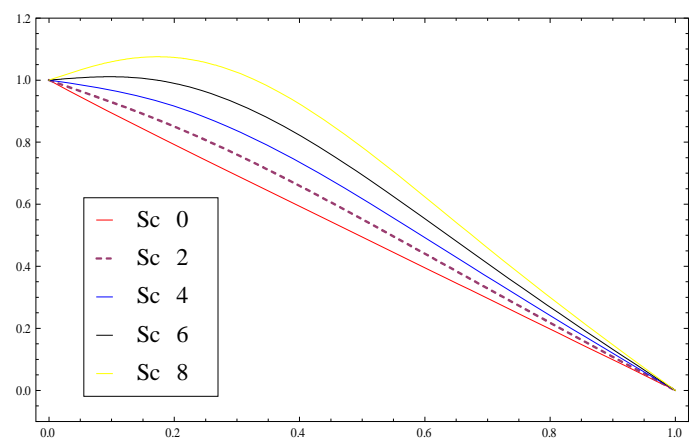

$$
\begin{array}{cl}
\text { FIGURE VII. } & \phi(\eta)_{\text {WITH }} S C_{\text {WHEN }} M=6 \\
& R e=10, \lambda=1, \alpha=0.6
\end{array}
$$

\section{CONCLUSIONS}

Slip flow and temperature jump boundary conditions are applied to solve the momentum and energy equations in a channel for the MHD second grade fluid. The nonlinear problems of velocity, energy and mass equation are solved by 
HAM. The effects of various parameters such as the magnetic parameter $M$, the Reynolds number $R e$, the velocity-slip parameter $\lambda$, the second-grade fluid parameter $\alpha$, the Eckert number $E c$, the Prandtl number $\mathrm{Pr}$, the Schmidt number $S c$ and the temperature-jump parameter $\alpha$ on velocity and thermal fields in the micro channel are studied through graphs and tables in detail. Some of the findings drawn from the investigation are listed as follows:

i) The skin friction coefficient $C_{f}$ increases by increasing $\operatorname{Re}$ and $\alpha$ but decreases with an increase of $M$ and $\lambda$;

ii) The Nusselt number $N u$ is an increasing function of $M, \lambda, \alpha, E c$ and an decreasing function of $\operatorname{Re}, \alpha, \operatorname{Pr}$, $K$ and $E c$.

\section{REFERENCES}

[1] M. Mooneym, (2013). Heat and mass transfer of MHD second order slip flow. Computer \& Fluids, 71, p. 426-434.

[2] M. Turkyilmazoglu, (2011). Analytic heat and mass transfer of the mixed hydrodynamic thermal slip MHD viscous flow over a stretching sheet. International Journal of Mechanical Sciences, 53, p .886-896.

[3] G. Singh, A.J. Chamkha, (2013). Dual solutions for second-order slip flow and heat transfer on a vertical permeable shrinking sheet. Ain Shams Engineering Journal.

[4] T.G. Fang, S.S Yao, (2010). Viscous flow over a shrinking sheet with a second order slip flow model. Commun Nonlinear Sci Numer Simulat ,15, p.1831-1842.

[5] B. Sahoo, (2010). Effects of slip, viscous dissipation and Joule heating on the MHD flow and heat transfer of a second-grade fluid past a radially stretching sheet. Applied Mathematics and Mechanics, vol.31, p. 159-173. DOI 10.1007/s10483-010-0204-7.

[6] C. Ye and X. N. Luo, (2012). High-order numerical methods of fractional-order Stokes' problem for heated generalized second grade fluid. Applied Mathematics and Mechanics, vol.33, p. 65-80. DOI10.1007/s10483-012-1534-8.

[7] I.G. Baoku, B.I. Olajuwon, A.O, Mustapha, (2013). Heat and mass transfer on a MHD third grade fluid with partial slip flow past an infinite vertical insulated porous plate in a porous medium. International Journal of Heat and Fluid Flow ,40, p. 81-88.

[8] T. Hayat, M. Awais, (2012). Three-dimensional rotating flow between two porous walls with slip and heat transfer. International Communications in Heat and Mass Transfer, 39, p.551-555.

[9] A.V. Rosca, L. Pop, (2013). Flow and heat transfer over a vertical permeable stretching/shrinking sheet with a second order slip. International Journal of Heat and Mass Transfer, 60, p.355-364.

[10] M. Mahantesh and M. Vajravelu, (2012). Second order slip flow and heat transfer over a stretching sheet with non-linear Navier boundary condition. International Journal of Thermal Sciences, 58, p.143-150.

[11] 11.B. Sahoo, S. Poncet, (2011). Flow and heat transfer of a third-grade fluid past an exponentially stretching sheet with partial slip boundary condition. International Journal of Heat and Mass Transfer, 54, p.5010-5019.

[12] S. SRINIVAS, P. B. A. REDDY and B. S. R. V. PRASAD, (2014). Effects of chemical reaction and thermal radiation on MHD flow over an inclined permeable stretching surface with nonuniform heat source/sink: an application to the dynamics of blood flow. Journal of Mechanics in Medicine and Biology, vol.14, p.1450067- 1450091. DOI: 10.1142/S0219519414500675.

[13] B. I. Olajuwon, (2011). Convection heat and mass transfer in a hydromagnetic flow of a second-grade fluid in the presence of thermal radiation and thermal diffusion. International communications in Heat and Mass Transfer 38, p.377-382.

[14] S.J. Liao, (1992). The Proposed Homophony Analysis Technique for the Solution of Nonlinear Problems. Ph.D. Thesis, Shanghai Jiao Tong University.

[15] K. Yakushima, M. Yamashita, K. Stub, (2007). An analytic solution of projectile motion with the quadratic resistance law using the homotropy analysis method. J. Phys.A: Mathematical and Theoretical, 40, p.8403-8416.

[16] V. Marinca, N. Herisanu, (2008). Application of optional homotopy asymptotic method for solving nonlinear equations arising in heat transfer. International communications in Heat and Mass Transfer, 35, p.710-715.

[17] M.M. Zhao, (2009). The Further Discussion for Homotopy Analysis Method and Their Modification. Ph.D. Thesis, Lan Zhou University.

[18] Z. Niu, (2010). A one-step optional homotopy analysis method for nonlinear differential equations. Commun Nonlinear Sci Numer Simulat,15, p.2026-2036.

[19] S. Srinivas, (2014). A. Vijayalakshmi, T. R. Ramamohan, A. S. Reddy, Hydromagnetic flow of a nanofluid in a porous channel with expanding or contrating walls. Journal of Porous Media, 17 (11), p.953-967. 